\title{
Development of Integrated Starter-generator Test System Based on Virtual Instrument
}

\author{
Lijie Chen ${ }^{1, a}$, Yanmin $\mathrm{Xu}^{1,2, \mathrm{~b}}$ \\ ${ }^{1}$ Guangdong Mechanical and Electrical College, Guangzhou 510000, China; \\ ${ }^{2}$ South China University of Technology, Guangzhou 510000, China. \\ a chenlijie168@163.com, ${ }^{b}$ xu.yanmin@mail.scut.edu.cn
}

Keywords: integrated starter-generator, hybrid electric vehicle, powertrain, test system.

Abstract. Integrated starter-generator (ISG) used in the hybrid power system is becoming more and more popular. In order to meet the test needs of ISG hybrid electric vehicle powertrain, the ISG hybrid assembly test platform based on virtual instrument was developed.

\section{Introduction}

\subsection{Peculiarity of ISG Hybrid Powertrain.}

As the energy resources shortage and environment protection have become the major challenge for the world, it is imperative to alter the energy and power system for vehicle industry, the electric vehicle has become the essential choice for such alteration [1]. Integrated starter-generator has been widely used in hybrid vehicles to reduce the engine idle fuel consumption by intelligent start-stop controlling, and to increase engine power and economy by auxiliary driving and energy recovering, so as to realize the reduction of exhaust gas pollution and fuel saving effect $[2,3,4]$.

Compared with the traditional vehicle, the key components of ISG power system of the hybrid vehicle have more signals to be measured in product verification and testing. So, the efficient test equipment is needed to improve development speed.

ISG hybrid system should be provided with rapid automatic starting and stopping, seasonable power compensation, deceleration or braking energy recovery and non contact electric braking. In order to realize the above four functions, a series of software and hardware system was developed according to the characteristics of the system, and then they have been combined together to carry out the validation of the indicators on a specific platform.

\subsection{Increasing Demand for the Test System of ISG Hybrid System.}

According to the performance of the system under different working conditions, a large number of complex and repeated improvements should be pro-posed during the development of software and hard-ware.

In the performances of hybrid powertrain, the durability of ISG hybrid system is one of the important symbols of the quality of ISG hybrid power system. Excellent performance needs good durability to fully play out. And for a hybrid system, its durability is al-so related to the safety of people and goods transport problems.

At the same time, with the rapid development of ISG hybrid power industry, the demand for the teaching system of ISG hybrid system is increasing. As a result, the construction of talented persons for technical service in automobile post market has be-come the urgent problem to be solved in the process of developing new energy vehicles. The vocational colleges and universities are trying to intercalate the electric car related courses, but do not have enough training facilities, coupled with that the technology of electric vehicles compared to the traditional automobile technology is very different, and more abstract. Theoretical teaching is difficult to meet the teaching objectives of electric vehicle related courses. So the development and application of equipment and institutions of all kinds of new energy vehicles have become practical problems of higher education and secondary occupation education. 
According to the development need of the industry and scientific research, the R \& D team of the author developed the ISG hybrid powertrain test verification and testing system, which can be directly used on the ISG hybrid vehicle powertrain performance test under various conditions. Especially, the performance of ISG motor and engine test, is conducive to the establishment of a unified, scientific ISG hybrid vehicle and parts assembly evaluation system, help the engineer to verify the strategy algorithm, shorten the development cycle, reduce the risk of development of hybrid electric vehicle and cost. The system has the function of working condition simulation test, and can display the working process of the system directly. It can be used in the experiment teaching of the new energy vehicle specialty in all kinds of vocational colleges.

\section{Hardware Structure Design}

\subsection{Test System Hardware Overall Structure.}

ISG hybrid system is mainly composed of engine, engine ECU, ISG motor, motor controller, battery and its management system, power transmission sys-tem, braking system and vehicle control system. The test system was developed mainly for the matching of ISG motor and engine performance, the functional verification and simulation of different working conditions of ISG hybrid system. Except for the hardware being tested, the hardware system also includes a data acquisition and processing center, a dynamometer, and sensors etc. The hardware framework of the test system is shown in figure 1.

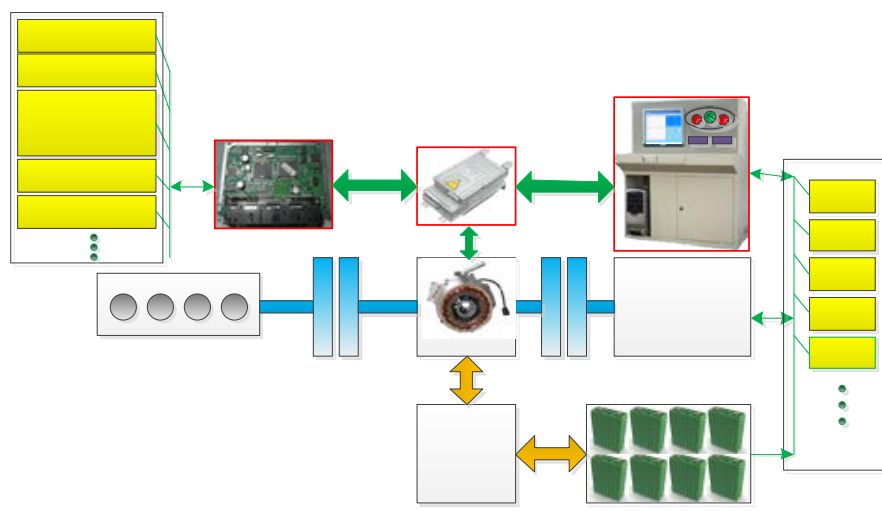

Fig. 1 Hardware framework of the test system

The data acquisition and processing center is mainly composed of the industrial control host computer, data acquisition card, display device and other components. The data acquisition cards mainly include analog input and output cards, digital input and output cards and CAN communication cards. Sensors include speed torque sensors, current sensors, voltage sensors, temperature sensors, etc. By connecting the CAN communication card to the CAN communication interface of controllers, the host computer can obtain the data transfer between the ECUs in order to reduce the complexity of the system.

\subsection{Test Process Analysis.}

The validation testing process can be divided into three stages.

The first stage: the curve of engine torque and speed can be obtained through the engine test bench experiment, and the engine real-time output power can be calculated at the same time. By importing simulation conditions set, whether the engine power meets the needs of maximum speed, acceleration and grade ability can be verified [5]. 




Fig. 2 The engine fuel rate

The second stage: the motor performance test, the torque speed curve of ISG motor can be obtained through the motor performance test, and the motor power can be calculated out. Whether the power of the motor meets the peak power of charging and discharging requirements in the specified working conditions can be verified [5].

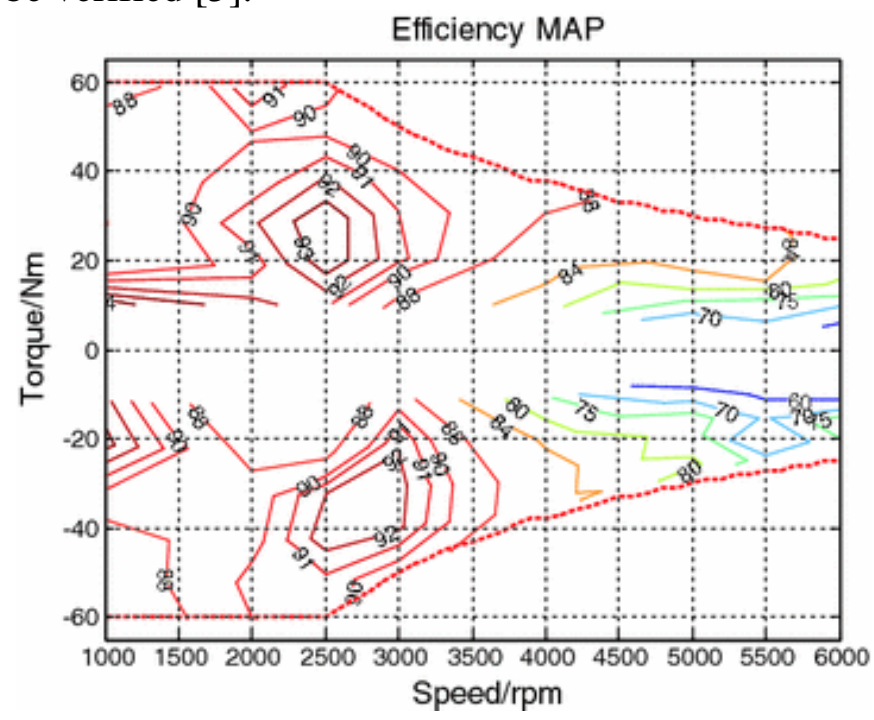

Fig. 3 The motor efficiency map

The third stage: Test the matching between engine and motor. The test items mainly include the torque and speed matching verification, intelligent starting and stopping control function verification, motor power assistance function verification, braking energy recovery function verification and comprehensive performance target verification, etc.. The torque speed matching verification test is mainly to verify the ISG motor and engine peak torque and speed value is to meet the maximum speed, maxi-mum grade ability and the acceleration time requirement of $0-100 \mathrm{~km} / \mathrm{h}$. The intelligent start stop control function verification test mainly includes the reasonability of ISG hybrid power system start and stop prerequisite, power generation efficiency, etc.. ISG motor's power assistance function test mainly includes the reasonability of the assistant power pro-vided by the ISG motor, the ability of power assisted driving of ISG motor and the evaluation of actual power assist effect. Braking energy recovery function verification mainly including the reasonability of ratio between the configuration regenerative braking and friction braking, the braking efficiency and energy recovery efficiency, etc.. The comprehensive performance target verification mainly includes the power, economy, and anticipated driving range of ISG hybrid powertrain.

\section{Design of System Software}

There are a large number of parameters to be collected and monitored in the ISG hybrid system test system. The data processing and user operation are complicated. In order to make the test system simple and easy to use, it must meet the requirements of intuitive interface, good interactive operation. So ap-plying visual monitoring system in the host computer, software of ISG hybrid powertrain test 
system was developed based on LabVIEW development environment, to simplify operation and interface, and realize real-time interactive and intuitive design requirements. Figure 4 is the design of the virtual measurement and control system platform for human-computer interaction interface program for the project preliminary development.

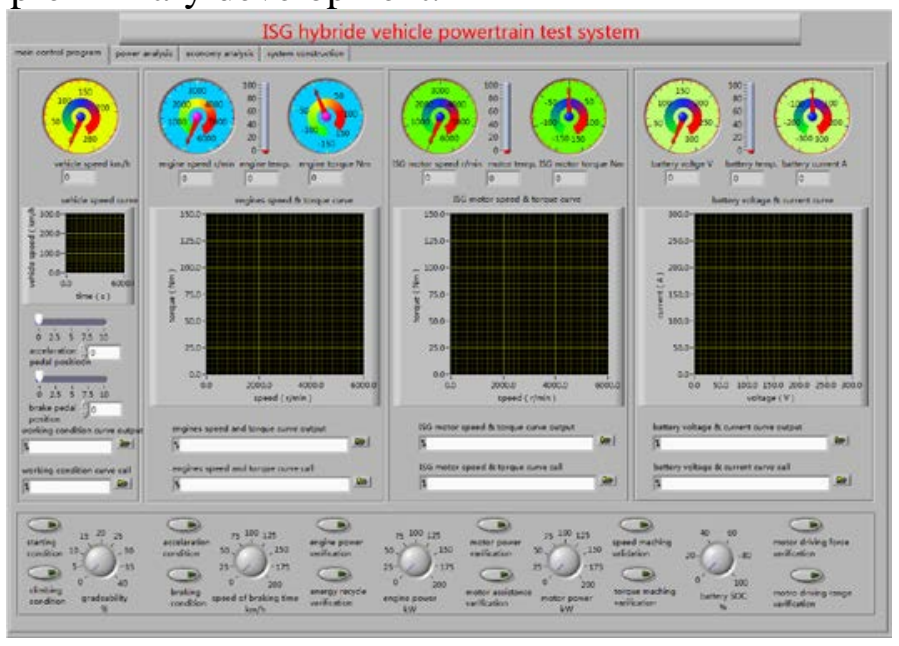

Fig. 4 Main screen interface

The graphical interface layout scheme has not on-ly rich curve display, but also real-time online monitoring and control functions, which fully meet the requirement of human-machine interface, convenient operation, intuitive real-time control etc..

\section{Conclusion}

Using high-speed industrial computer as the main control part of the whole system, the ISG hybrid powertrain test and verification system developed in this project improved the system operation ability, and provided hardware guarantee for the realization of accurate and fast operation. The efficient and humanized human-computer interaction measurement and control system based on LabVIEW, realized the functional requirements of the control system through convenient control, visual display, rich feature graphical man-machine interface, which reduced development costs, and improved operability, intuitive, and convenient for the subsequent product up-grades and maintenance.

The ISG hybrid system developed can meet the requirements of the whole working condition hard-ware in the loop test function of ISG hybrid power-train system. Based on the ISG hybrid electric vehicle simulation, using ISG motor hardware in the loop test method, the comprehensive performance of the system can be tested and verified. Real-time data display and data analysis system can facilitate the analysis of experimental observation, function reveal and online analysis.

\section{References}

[1]. YANG Yang, SU Ling, QIN Datong, et al. Energy management strategy for hybrid electric vehicle based on system efficiency and battery life optimization. Wuhan University Journal of Natural Sciences, Vol.19(2014)No.3,p. 269-276.

[2]. Ralf Kruse, Heinz Schäfer, Ludwig Wähner. Integrated starter-generator for the $42 \mathrm{~V}$ electrical system. ATZ worldwide, Vol. 104(2002)No. 7, p. 13-16.

[3]. Hu Zhong, Guo-qiang Ao, Feng Wang. Torque distribution strategy for integrated starter/ generator hybrid bus implemented by fuzzy algorithm. Journal of Shanghai Jiaotong University (Science), Vol. 13(2008)No. 3,p. 323-329.

[4]. Eckhard Karden. Energy Management and Storage Technologies in Micro-Hybrid Vehicles. Auto Technology, Vol. 5(2005)No.6,P. 56-59. 
[5]. Hongtao Peng, Zheng Li, Bin Chen et al. Development for Control Strategy of ISG Hybrid Electric Vehicle Based on Model. In SAE-China and FISITA (eds.), Proceedings of the FISITA 2012 World Automotive Congress, Beijing, from 27th-30th November 2012, p. 333-342. 